\title{
Flora da Bahia: Costaceae
}

\section{Alessandra Bertoso Jardim ${ }^{1, a}$, Daniela Santos Carneiro-Torres ${ }^{*}$, Reyjane Patrícia de Oliveira ${ }^{1, b}$ \& Ana Maria Giulietti ${ }^{1,2, c}$}

${ }^{1}$ Programa de Pós-Graduação em Botânica, Departamento de Ciências Biológicas, Universidade Estadual de Feira de Santana, Feira de Santana, Bahia, Brasil.

2 Instituto Tecnológico Vale de desenvolvimento, Belém, Pará, Brasil \& Royal Botanic Gardens, Kew, TW9 3 AB, Inglaterra.

Resumo - É apresentado aqui o tratamento taxonômico de Costaceae no estado da Bahia, Brasil. Foram reconhecidos os gêneros Chamaecostus, com duas espécies (C. cuspidatus e C. subsessilis), e Costus, com três (C. arabicus, C. scaber e C. spiralis). São apresentados chave de identificação, descrições, ilustrações, comentários e mapas de distribuição geográfica das espécies no Estado.

Palavras-chave adicionais: Brasil, Chamaecostus, Costus, florística, Mata Atlântica.

\begin{abstract}
Flora of Bahia: Costaceae) - The taxonomic treatment of the Costaceae from the state of Bahia, Brazil, is presented here. Five species are recognized, two species of Chamaecostus (C. cuspidatus and C. subsessilis) and three species of Costus (C. arabicus, C. scaber and C. spiralis). Identification keys, descriptions, illustrations, notes and maps of geographic distribution of the species in Bahia are presented.
\end{abstract}

Additional key words: Atlantic forest, Brazil, Chamaecostus, Costus, floristics.

\section{COSTACEAE}

Ervas perenes; rizoma com ramificação simpodial; caules aéreos não ramificados, retos ou em espiral. Folhas espiraladas, raramente rosuladas, pecioladas; bainha tubulosa, fechada; lígula truncada ou bilobada; limbo inteiro, simples, lanceolado, elíptico ou obovado, peniparalelinérveo. Inflorescências terminais, espigas compactas, alongadas ou capitadas, ou raramente flores axilares; brácteas densamente imbricadas, com ou sem apêndice apical foliáceo (calo), glândula nectarífera linear, abaixo do ápice; bractéolas carenadas ou tubulosas. Flores bissexuadas, zigomorfas; sépalas 3, unidas, formando um cálice tubuloso, trilobado; pétalas 3, unidas entre si geralmente até a metade; labelo petaloide formado pela fusão de 5 estaminódios; estame 1, filete achatado, ligeiramente petaloide, antera biteca, introrsa, rimosa; ovário ínfero, bi ou trilocular, estilete filiforme, entre as tecas, estigma bilamelado ou capitado, óvulos numerosos, placentação axilar; nectários septais. Frutos cápsulas loculicidas, cálice persistente. Sementes angular-ovoides, marrom-escuras ou pretas, arilo branco.

Costaceae integra a ordem Zingiberales (APG IV 2016), abrange sete gêneros e cerca de 120 espécies, e possui distribuição nos trópicos e subtrópicos do Velho e do Novo Mundo (Maas 1972, 1977). Para o Brasil,

\footnotetext{
*Autora para correspondência: dscarneiro@hotmail.com;

aallejard@yahoo.com.br, ${ }^{b}$ rpatricia@uefs.br,

cana.giulietti@vale.org

Editor responsável: Alessandro Rapini

Submetido: 30 maio 2016; aceito: 21 out. 2016

Publicação eletrônica: 27 out. 2016; versão final: 1 nov. 2016
}

são registrados três gêneros: Chamaecostus C.Specht \& D.W.Stev., com seis espécies, e Costus L., com 16 espécies, ambos de ocorrência predominante na Região Norte, além de Dimerocostus Kuntze (D. strobilaceus Kuntze, no Acre) (Maas-van der Kamer \& Maas 2003; Souza \& Lorenzi 2008; Maas \& Maas-van der Kamer 2010; BFG 2015).

\section{Chave para os gêneros}

1. Ervas acaulescentes ou com caule aéreo até $1 \mathrm{~m}$ alt.; brácteas membranáceas, com apêndice apical foliáceo (calo); bractéolas tubulosas; estigma capitado 1. Chamaecostus

1'. Ervas a arvoretas com caule aéreo maior que $1 \mathrm{~m}$ alt.; brácteas coriáceas, sem apêndice apical; bractéolas conduplicadas; estigma bilamelado ..........

2. Costus

1. Chamaecostus C.D.Specht \& D.W.Stev.

Ervas acaulescentes ou com caule aéreo até $1 \mathrm{~m}$ alt. Folhas rosuladas ou espiraladas, ápice acuminado a longo-acuminado. Inflorescências frequentemente capitadas; brácteas verdes, membranáceas, foliáceas; calo estreitamente triangular a deltoide, mucronado; bractéolas membranáceas, tubulosas. Flores com cálice verde, de lobos triangulares; tubo da corola maior que o cálice, lobos lanceolados; labelo mais alto que a corola, laranja, amarelo ou branco; antera com conectivo triangular; ovário com óvulos bisseriados; estigma capitado. Cápsulas brancas, elipsoides a globosas.

Chamaecostus inclui seis espécies e distribuição restrita à América do Sul, ocorrendo nas Guianas, Bolívia e Brasil (Specht \& Stevenson 2006). Na Bahia, ocorrem duas espécies, C. cuspidatus e C. subsessilis, na Mata Atlântica e em áreas de transição para $o$ 
Cerrado, respectivamente. As espécies deste gênero que vivem em áreas com clima seco perdem todas as folhas durante o verão, rebrotando no início da estação chuvosa (Maas 1972).

\section{Chave para as espécies}

1. Folhas rosuladas, com lâmina pubescente em ambas as faces; corola e labelo laranja; antera obtusa

1.1. C. cuspidatus

1'. Folhas espiraladas, com lâmina densamente estrigosa em ambas as faces; corola e labelo amarelos pontuados de vermelho-acastanhado; antera caudada 1.2. C. subsessilis

1.1. Chamaecostus cuspidatus (Nees \& Mart.) C.D.Specht \& D.W.Stev., Taxon 55(1): 158. 2006.

Figuras $1 \mathrm{~A}, \mathrm{~B}$ e 2.

Ervas ca. $50 \mathrm{~cm}$ alt. Folhas rosuladas; pecíolo 1-3 mm compr.; bainha 5-10 mm larg.; lígula truncada, 1$2 \mathrm{~mm}$ compr.; lâmina obovada a elíptica, $11-18 \times 3,5$ $6(-7,5) \mathrm{cm}$, ápice acuminado, base cuneada, pubescente em ambas as faces. Inflorescências 3-8floras; brácteas ca. $40 \times 15 \mathrm{~mm}$ compr.; calo 2-11 mm compr.; bractéolas 25-30 $\mathrm{mm}$ compr. Flores com cálice 30-40 mm compr.; corola laranja, 55-60 mm compr., tubo 25-30 mm compr., lobos ca. $35 \mathrm{~mm}$ compr.; labelo laranja, 50-70 mm compr.; estame amarelo, ca. 1,5 mm compr., antera obtusa. Cápsulas elipsoides a globosas, ca. 1,5 cm compr.

Ocorre apenas no Brasil, sendo exclusiva da Mata Atlântica da Bahia, Rio de Janeiro e Minas Gerais (Maas \& Maas-van der Kamer 2010; Maas \& Maas 2016). F8, H8, H9, I8: floresta ombrófila do sul da Bahia. Coletada com flores em maio, e de outubro a janeiro, e com frutos em janeiro e agosto.

Material selecionado - Belmonte, $15^{\circ} 51^{\prime} \mathrm{S}, 38^{\circ} 52^{\prime} \mathrm{W}, 22$ jan. 1985 (fl., fr.), L.A. Mattos-Silva et al. 1804 (CEPEC); Gandu, $13^{\circ} 44^{\prime} 38^{\prime \prime S}, 39^{\circ} 29^{\prime} 13^{\prime \prime W}, 21$ out. 1970 (f1.), T.S. Santos et al. 1157 (CEPEC); Itapebi, 155'03"S, 39³2'02"W, 19 maio 1979 (fl.), T.S. Santos et al. 828 (CEPEC); Porto Seguro, 16 $27^{\circ} 00^{\prime \prime} \mathrm{S}$, 39 03'54"W, 17 maio 1971 (fl., fr.), T.S. Santos et al. 1654 (CEPEC); Valença, 1322'12"S, 3904'22"W, 11 ago. 1980 (fl., fr.), L.A. Mattos-Silva et al. 1053 (CEPEC); Wenceslau Guimarães, 13ํ1'13"S, 39²8'44"W, 15 maio 1992 (fl.), W.W. Thomas et al. 9329 (CEPEC).

Chamaecostus cuspidatus assemelha-se a $C$. subsessilis quanto ao hábito herbáceo, brácteas verdes, folhas espiraladas com limbo oboval a elíptico e bainhas que recobrem os entrenós, diferindo principalmente pela corola laranja (vs. amarela em $C$. subsessilis). A distribuição geográfica dessas duas espécies apresenta pequena sobreposição: $C$. cuspidatus ocorre na Mata Atlântica e C. subsessilis em áreas de transição com o cerrado, no leste do Brasil (André et al. 2015). Chamaecostus cuspidatus encontra-se na lista oficial das espécies brasileiras ameaçadas de extinção (IBAMA 1992; MMA 2008) e, na Bahia, não é coletada desde 1992.
1.2. Chamaecostus subsessilis (Nees \& Mart.) C.Specht \& D.W.Stev., Taxon 55(1): 158. 2006.

Figuras $1 \mathrm{C}-\mathrm{E}$ e 2.

Ervas ca. $25 \mathrm{~cm}$ alt. Folhas espiraladas; pecíolo 1$3 \mathrm{~mm}$ compr.; bainha 5-20 mm larg.; lígula truncada, ca. $1 \mathrm{~mm}$ compr.; lâmina obovada a elíptica, 5-30 × 3$13 \mathrm{~cm}$, ápice acuminado, base cuneada, densamente estrigosa em ambas as faces. Inflorescências 1-4floras; brácteas ca. $40 \times 5-15 \mathrm{~mm}$ compr.; calo 5-35 mm compr.; bractéolas 25-32 mm compr. Flores com cálice 21-41 mm compr.; corola amarela, geralmente pontuada de vermelho-acastanhada, 55-70 $\mathrm{mm}$ compr., tubo 25-30 mm compr., lobos 30-40 mm compr.; labelo amarelo, pontuado de vermelho-acastanhado, 60-70 cm compr.; estame amarelo, 35-50 mm compr., antera caudada. Cápsulas elipsoides, $1-1,8 \mathrm{~cm}$ compr.

Ocorre apenas na América do Sul (Maas \& Mass 2003); no Brasil, ocorre nas Regiões Norte, CentroOeste, Sudeste e Nordeste (Maas \& Maas-van der Kamer 2010; Maas \& Maas 2016). G8, H7, H8, I8, J8: cerrado, mata mesófila e mata atlântica. Coletada com flores de janeiro a maio e em setembro e com frutos de dezembro a março.

Material selecionado - Itabuna, $14^{\circ} 47^{\prime} 09^{\prime \prime} \mathrm{S}, 39^{\circ} 16^{\prime} 48^{\prime \prime} \mathrm{W}, 25$ maio 1966 (fl.), R.P. Belém 2274 et al. (CEPEC, UNB); Itamaraju, $17^{\circ} 02^{\prime} 20^{\prime \prime S}, 39^{\circ} 31^{\prime} 51^{\prime \prime} \mathrm{W}, 8$ set. 1978 (fl.), S.A. Mori et al. 10753 (CEPEC); Itapé, 1453'52"S, 39²5'15"W, 2 mar. 1978 (fl., fr.), S.A. Mori et al. 9351 (CEPEC); Itororó, 1507'01"S, 4004'12"W, 12 jan. 1971 (fl., fr.), T.S. Santos et al. 1301 (CEPEC); Jussari, $15^{\circ} 11^{\prime} 27^{\prime \prime S}, 39^{\circ} 29^{\prime} 42^{\prime \prime} \mathrm{W}, 16$ maio 1995 (fl.), W.W. Thomas et al. 10858, (CEPEC); Porto Seguro, 16 $6^{\circ} 7^{\prime} 00^{\prime \prime} \mathrm{S}, 39^{\circ} 03^{\prime} 54^{\prime \prime} \mathrm{W}, 18$ maio 1971 (fl.), T.S. Santos et al. 1661 (CEPEC); São Desidério, 12²43'S,

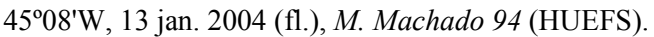

André et al. (2015) consideraram Chamaecostus subsessilis, como tradicionalmente circunscrita, parafilética e propuseram uma nova espécie, $C$. acaulis (S.Moore) T.André \& C.D.Specht, que não ocorre na Bahia. Segundo essa nova delimitação, C. subsessilis s. str. inclui ervas caulescentes, com folhas menores, estrigosas a glabras, que ocorrem a leste do vale do rio Araguaia, na maior parte do Planalto Central e na transição entre o Cerrado e a Mata Atlântica (André et al. 2015).

\section{Costus L.}

Ervas a arvoretas com caule aéreo de 1-5 m alt. Folhas espiraladas, ápice agudo a acuminado. Inflorescências ovoides, fusiformes ou estreitamente cilíndricas, multifloras; brácteas coriáceas, verdes, em tons vermelhos ou laranja, sem calo; bractéolas conduplicadas. Flores com cálice de lobos triangulares; tubo da corola da altura do cálice, lobos estreitamente elípticos; labelo da mesma altura ou mais alto que a corola, branco, amarelo, vermelho-salmão ou vermelho-purpúreo; antera com conectivo elíptico, obtusa; ovário com óvulos bisseriados; estigma bilamelado. Cápsulas brancas, elipsoides a globosas. 


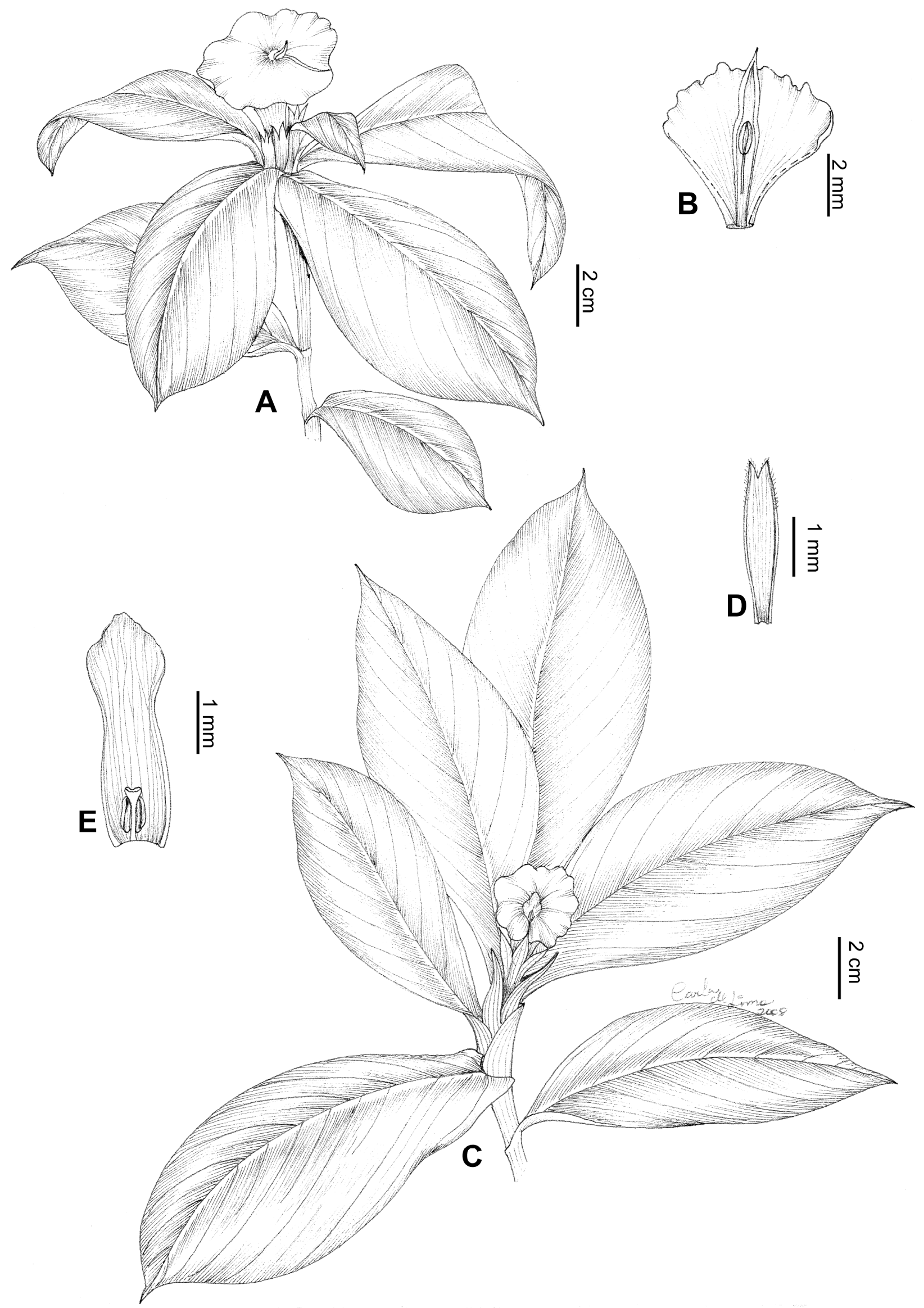

Figura 1. A, B. Chamaecostus cuspidatus: A- ramo com inflorescência; B- corola, labelo. C-E. C. subsessilis: C- ramo com inflorescência; D- bractéola, face interna; E- labelo, estame e estigma. (A- Santos 828; B- Thomas 9329; C, D- Mori 9351; E- Santos1301). 
Costus inclui 45 espécies, com distribuição nos trópicos e subtrópicos das Américas (Specht \& Stevenson 2006). Várias espécies podem se reproduzir vegetativamente (brotação); a forma mais comum é através de fragmentação do rizoma, quando partes do rizoma são rompidas e passam a funcionar como plantas independentes. As inflorescências crescem em largura e comprimento quando começam a frutificar e, na maioria das espécies, nascem no final do ramo, mas podem sair também diretamente do rizoma (Silva \& Parente 2004).

\section{Chave para as espécies}

1. Lâmina foliar de base cordada e face abaxial completamente pubérula a velutina; brácteas verdes na face externa; labelo branco, 50-70 mm compr. ...

2.1. C. arabicus

1'. Lâmina foliar de base cuneada a arredondada e face abaxial glabra passando a pubérula próximo ao ápice; brácteas vermelhas ou laranja-avermelhadas em ambas as faces; labelo amarelo ou vermelhoróseo, 20-30 $\mathrm{mm}$ compr.

2. Lâmina foliar elíptica a oboval; bractéolas 912(-17) $\mathrm{mm}$ compr.; cálice 30-70 mm compr.; corola 35-40 $\mathrm{mm}$ compr., laranja a amarela; labelo amarelo 2.2. C. scaber

2'. Lâmina foliar estreitamente elíptica a estreitamente oboval; bractéolas 15-29 mm compr.; cálice 6-13(-15) $\mathrm{mm}$ compr.; corola 45-60 $\mathrm{mm}$ compr., vermelho-salmão a vermelho-purpúreo; labelo vermelho-róseo .........

2.3. C. spiralis

2.1. Costus arabicus L., Sp. Pl. 1: 2. 1753.

Figuras $3 \mathrm{~A}-\mathrm{C}$ e 4.

Ervas 1-3 m alt. Folhas com pecíolo 2-7 mm compr.; bainha 5-15 mm larg.; lígula truncada, 2-10 mm compr.; lâmina estreitamente ovada a obovada, 9$22 \times 3-10 \mathrm{~cm}$, ápice agudo, base cordada, face adaxial glabra, a abaxial pubérula a velutina. Inflorescências ovoides a fusiformes, $6-13 \mathrm{~cm}$ compr.; brácteas verdes na face externa, vermelhas na interna, largamente ovadas, 25-45 mm compr.; bractéolas 20-34 mm. compr. Flores com cálice vermelho-rosado, 11-14 (27) $\mathrm{mm}$ compr.; corola branca, $60-70 \mathrm{~mm}$ compr., tubo 15-20 mm compr., lobos 40-50 mm compr.; labelo branco, largamente obovado quando estendido, 50-70 mm compr., lobos laterais geralmente púrpura, o mediano com mancha central amarela; estame branco, 40-50 mm compr.; estigma bilamelado. Cápsulas elipsoides, $1-1,8 \mathrm{~cm}$ compr.

Ocorre nas Antilhas e América do Sul tropical (Maas \& Maas 2003); no Brasil, distribui-se em todas as Regiões, mas no Nordeste, apenas nos estados da Bahia e do Maranhão (Maas \& Maas 2016). G8, H8, I8, J8: floresta ombrófila do sul da Bahia, em áreas próximas a rios e em plantações de cacau. Coletada com flores em abril e de setembro a dezembro e com frutos de maio a julho.

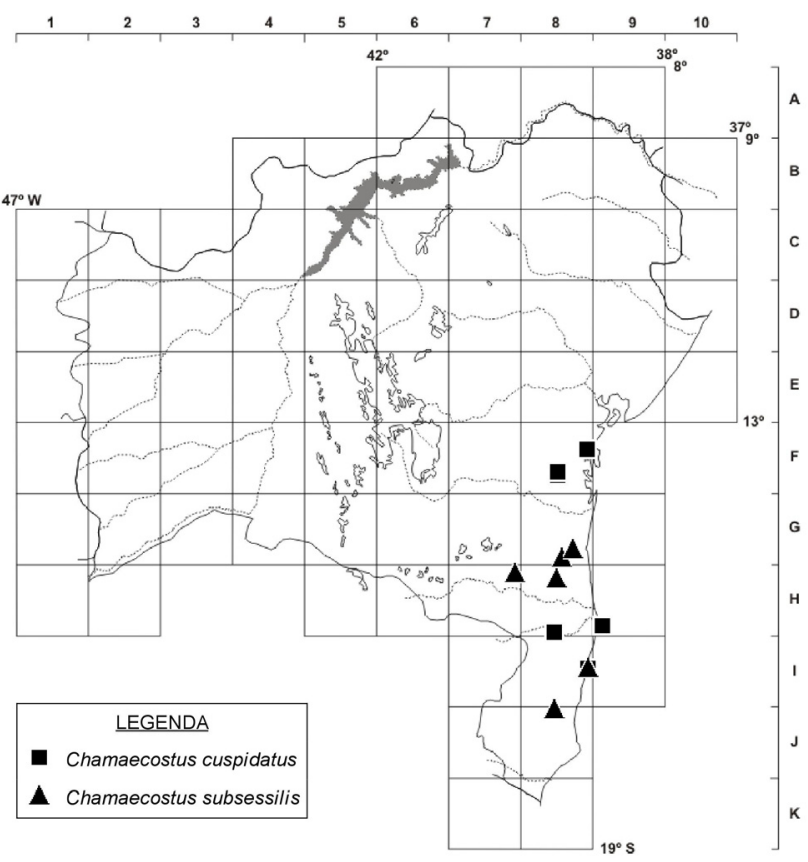

Figura 2. Mapa de distribuição geográfica de Chamaecostus cuspidatus e C. subsessilis no estado da Bahia.

Material selecionado - Alcobaça, $17^{\circ} 24^{\prime} 39^{\prime \prime} \mathrm{S}, 39^{\circ} 35^{\prime} 48^{\prime \prime} \mathrm{W}, 3$ abr. 1971 (fl.), T.S. Santos et al. 1548 (CEPEC); Canavieiras, 15040'35"S, 3859'52"W, 12 jul. 1978 (fl., fr.), T.S. Santos et al.

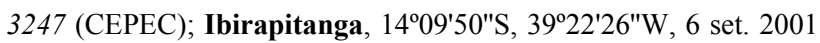
(fl.), D.L. Santana et al. 527 (CEPEC); Ilhéus, $14^{\circ} 48^{\prime} \mathrm{S}, 39^{\circ} 10^{\prime} \mathrm{W}, 22$ maio 2003 (fl.), L.A. Mattos-Silva et al. 4739 (CEPEC); Itacaré, 14'16'40"S, 3859'49"W, 14 dez. 1992 (fl.), A.M. Amorim et al. 949 (CEPEC); Maraú, 1406'10"S, 3900'54'’W, 18 maio 1980 (fl., fr.), R.M. Harley et al. 22226 (CEPEC); Porto Seguro, 16 $27^{\circ} 00^{\prime \prime S}$, 3903'54"W, 11 nov. 1998 (fl.), W.W. Thomas et al. 11304 (CEPEC); Una, 15²9'S, 39¹9'W, 15 abr. 1999 (fl.), L.A. Mattos-

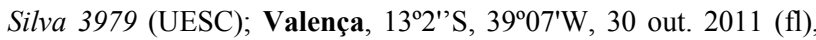
E.N. Mattos 709 (HUEFS).

Costus arabicus se destaca prontamente pela base da folha geralmente cordada, o que raramente acontece no gênero. É utilizada como medicinal e o extrato etanólico e hexânico do seu rizoma apresenta potencial antibacteriano e antifúngico (Tintino et al. 2013).

\subsection{Costus scaber Ruiz \& Pav., Fl. Peruv. 1: 2; t. 3.} 1798.

Figuras 3D-H e 4.

Ervas 1-3 m alt. Folhas com pecíolo 2-10 $\mathrm{mm}$ compr.; bainha 5-15(-20) mm larg.; lígula truncada, 2-12 mm compr.; lâmina elíptica a oboval, 10-34 × 3$11 \mathrm{~cm}$, ápice agudo, base cuneada a arredondada, face adaxial esparsamente pilosa a glabra, face abaxial glabra passando a pubérula próximo ao ápice. Inflorescências ovoides a estreitamente cilíndricas, 4$11 \mathrm{~cm}$ compr.; brácteas vermelhas a laranjaavermelhadas em ambas as faces, coriáceas, largamente ovadas, $20-35 \mathrm{~mm}$ compr.; bractéolas 9-12 $(-17) \mathrm{mm}$ compr. Flores com cálice vermelho, 30-70 $\mathrm{mm}$ compr.; corola laranja a amarela em ambas as faces, 35-40 mm compr., tubo ca. $1 \mathrm{~cm}$ compr., lobos 


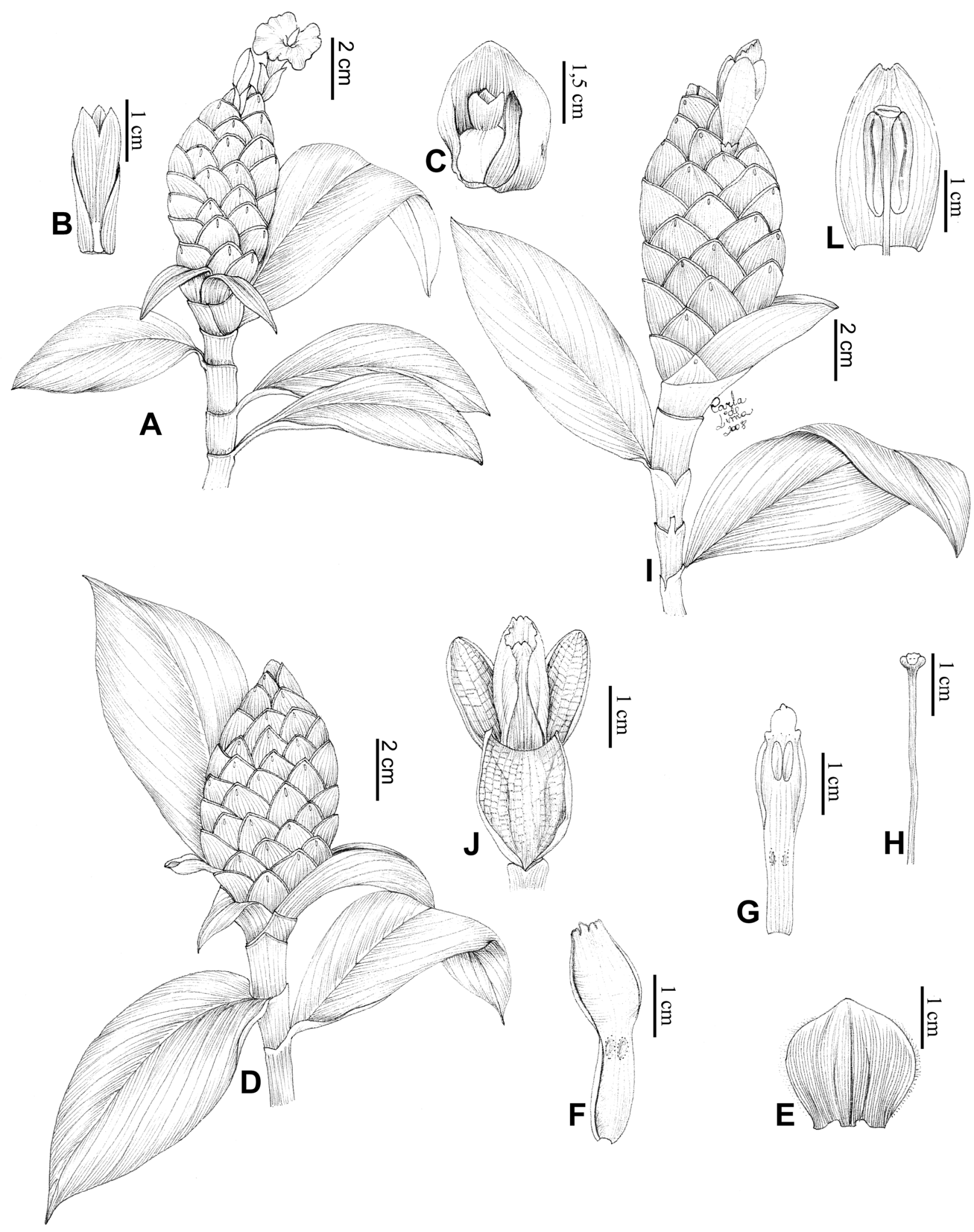

Figura 3. A-C. Costus arabicus: A- ramo com inflorescência; B- bractéola e cálice; C- bráctea, bractéola e cápsula com cálice persistente. D-H. C. scaber: D- ramo com inflorescência; E- bráctea, face externa; F- labelo, face interna; G- estame; H- estilete e estigma. I-L. C. spiralis: I- ramo com inflorescência; J- flor; L- labelo, estame e estigma. (A, B- Santos 1548; C- Mattos-Silva 4739; D, E- Maas 6972; F-H- Mori 9551; I- Maas 6970; J-L- Moraes 507).

ca. $30 \mathrm{~mm}$ compr.; labelo amarelo, oblongo-obovado quando estendido, 20-30 mm compr., lobos laterais encurvados, formando um tubo delgado, vermelhopurpúreo, o mediano branco; estame vermelho a 


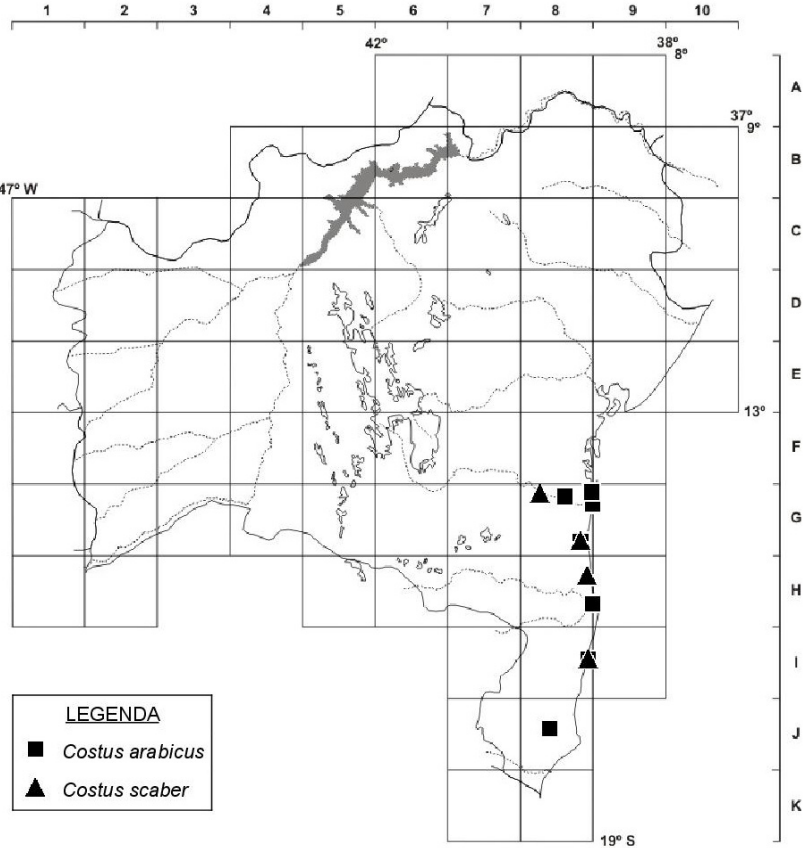

Figura 4. Mapa de distribuição geográfica de Costus arabicus e C. scaber no estado da Bahia.

laranja-avemelhado, ápice amarelo, 20-25 mm compr.; estigma bilamelado. Cápsulas elipsoides a subglobosas, 0,7-1,2 cm compr.

Distribui-se em toda a América do Sul tropical (Maas \& Maas 2003); no Brasil, ocorre nas Regiões Norte, Centro-Oeste (Mato Grosso), Sudeste (Espírito Santo), Sul (Santa Catarina) e Nordeste (Pernambuco e Bahia) (Maas \& Maas 2016). G8, H8, I8: floresta ombrófila, próximo a rios e em plantações de cacau, mata mesófila e restinga. Coletada com flores de março a julho e com frutos de fevereiro a março.

Material selecionado - Ilhéus, $14^{\circ} 48^{\prime} \mathrm{S}, 39^{\circ} 10^{\prime} \mathrm{W}, 24$ nov. 1987 (fl.), P.J.M. Maas et al. 6972 (CEPEC); Ipiaú, 1408'13"S, 3944'02"W, 6 mar. 1978 (fl., fr.), S.A. Mori et al. 9551 (CEPEC); Porto Seguro, 16 $27^{\prime} 00^{\prime \prime S}, 39^{\circ} 03^{\prime} 54^{\prime \prime W}, 24$ jun. 1967 (fl.), J.P. Lanna et al. 1512 (CEPEC); Una, 1517'34"S, 3904'30"W, 11 jul. 1978 (fl.), T.S. Santos et al. 3237 (CEPEC).

Costus scaber assemelha-se a C. spiralis quanto à coloração das brácteas e tamanho do labelo, diferenciando-se principalmente pela cor da corola e do labelo: em $C$. scaber, a corola é laranja a amarela e o labelo amarelo, enquanto em $C$. spiralis, ambos são vermelho-purpúreos. $\mathrm{Na}$ ausência da corolação das flores, as medidas das peças florais devem ser considerada: em C. spiralis, elas são maiores que em C. scaber.

2.3. Costus spiralis (Jacq.) Roscoe, Trans. Linn. Soc. London 8: 350. 1807.

Figuras 3I-L, 5 e 6.

Ervas 1-3,5 m alt. Folhas com pecíolo 2-17 $\mathrm{mm}$ compr.; bainha 5-20 mm larg.; lígula truncada, 2-10 $\mathrm{mm}$ compr.; lâmina estreitamente elíptica a estreitamente oboval, 8-30 × 5-14 cm, ápice agudo a acuminado, base cuneada a arredondada, face adaxial glabra, face abaxial glabra passando a pubérula próximo ao ápice. Inflorescências ovoides, 4-11(-22) cm compr.; brácteas vermelhas em ambas as faces, coriáceas, largamente ovadas, 20-40 mm compr.; bractéolas 15-29 $\mathrm{mm}$ compr. Flores com cálice vermelho-purpúreo, 6-13 $\mathrm{mm}$ compr.; corola vermelho-salmão a vermelho-purpúreo em ambas as faces, 45-60 mm compr., tubo ca. $1 \mathrm{~cm}$ compr., lobos 35-45 mm compr.; labelo vermelho-róseo, oblongoobovado quando estendido, 25-30 mm compr., lobos laterais encurvados, formando um tubo delgado, vermelho, lobo mediano branco; estame vermelho, ápice amarelo, 25-30 mm compr.; estigma bilamelado. Cápsulas elipsoides, $1-1,3 \mathrm{~cm}$ compr.

Distribui-se em toda a América do Sul tropical, exceto na região andina (Maas \& Maas 2003); no Brasil, ocorre em todas as Regiões (Maas \& Maas 2016). C7, D7, E7, E8, E9, F3, F8, G3, G8, H8, J8: floresta ombrófila, cerrado, mata estacional semidecídua, restinga, áreas de mata próximas a rios e em plantações de cacau. Coletada com flores de janeiro a julho e com frutos em março.

Material selecionado - Cachoeira, $12^{\circ} 32^{\prime} \mathrm{S}, 39^{\circ} 05^{\prime} \mathrm{W}, 4$ jul. 1980 (fl.), Grupo Pedra do Cavalo 456 (HUEFS); Cairu, 13²9'13"S, 3902'38"W, 15 jul. 1981(fl.), A.M. Carvalho et al. 791,

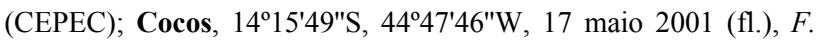
França 3673 (HUEFS); Conceição de Feira, 12³9'S, 38º3'W, 31 jul. 1980 (fl., fr), L.R. Noblick 1905 (HUEFS); Correntina, 1320'34"S, 44³8'13"W, 20 abr. 1980 (fl.), R.M. Harley et al. 21844 (CEPEC); Dom Macedo Costa, 1256'S, 39¹0'W, 5 jul. 1985 (fl., fr), L.R. Noblick 3987 (CEPEC, HUEFS,); Feira de Santana, $12^{\circ} 15^{\prime}$ 'S 38 $58^{\prime}$ W, 10 maio 1984 (fl.), L.R. Noblick 3170 (CEPEC, HUEFS); Ibirapitanga, $14^{\circ} 09^{\prime} 50^{\prime \prime} \mathrm{S}, 39^{\circ} 22^{\prime} 26^{\prime \prime} \mathrm{W}, 3$ mar. 1979 (fl., fr.), S.A. Mori et al. 11599 (CEPEC); Ilhéus, $14^{\circ} 48^{\prime} \mathrm{S}, 39^{\circ} 10^{\prime} \mathrm{W}, 12$ jul. 1988 (fl., fr.), J.L. Hage 2256 (CEPEC, HUEFS). Itaberaba,

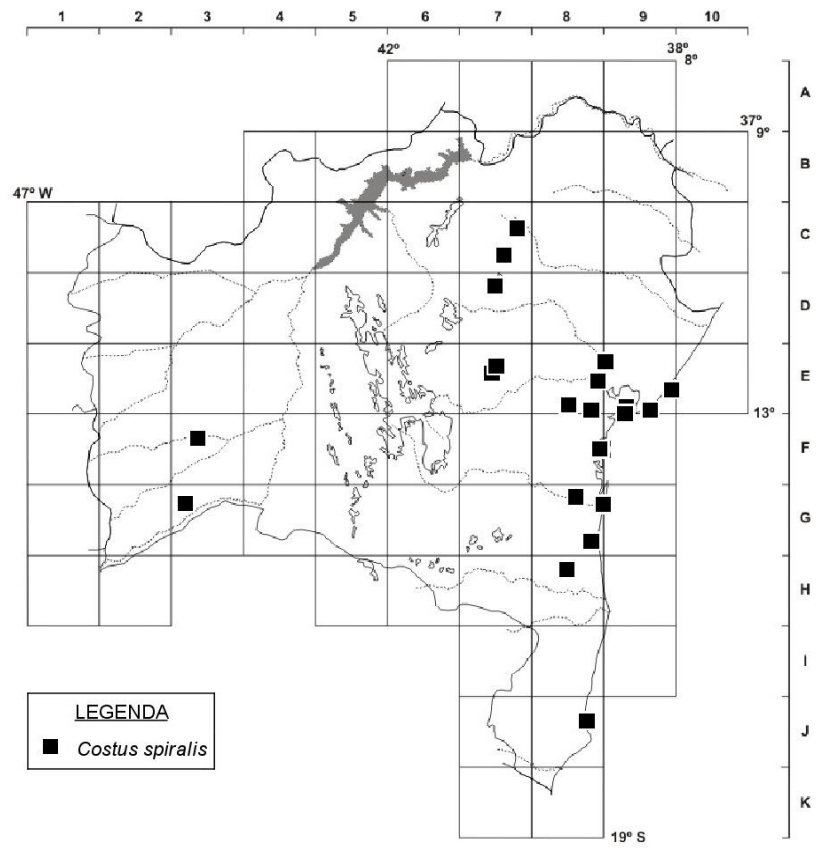

Figura 5. Mapa de distribuição geográfica de Costus spiralis no estado da Bahia. 

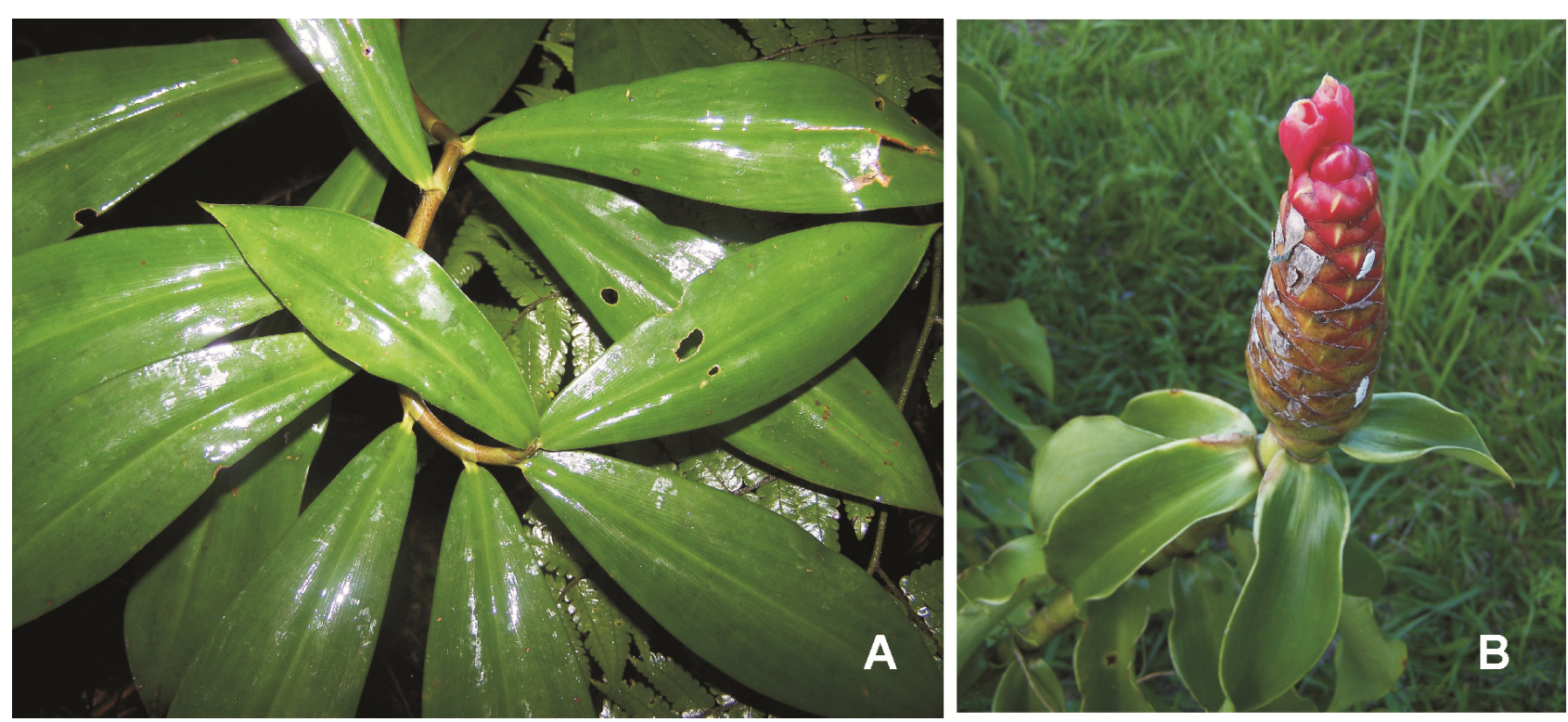

Figura 6.A, B. Costus spiralis: A- ramo; B- ramo com inflorescência (Fotos: J. Jardim).

$12^{\circ} 24^{\prime} 55^{\prime \prime S}, 40^{\circ} 32^{\prime 2} 22^{\prime \prime W}, 18$ jan. 2006 (fl.), L.P. Queiroz 12085 (HUEFS); Itacaré, $14^{\circ} 16^{\prime} 40^{\prime \prime} \mathrm{S}, 38^{\circ} 59^{\prime} 49^{\prime \prime} \mathrm{W}, 28$ jan. 1977 (fl.), R.M. Harley et al.18341 (CEPEC); Itaparica, 12²5 $13^{\prime} 6^{\prime \prime S}, 38^{\circ} 40^{\prime} 44^{\prime \prime} \mathrm{W}$,

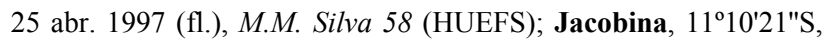
40²9'40"W, 19 abr. 2009 (fl., fr.), M.L. Guedes et al. 14855 (ALCB); Jussari, 15¹1'27"S, 39²9'42"W, 5 fev. 1998 (fl.), H.O. Pengel et al. 01 (CEPEC). Pindobaçu, 10 45'12"S, 40²3'5"W, 12 ago. 1999 (fl., fr.), E.B. Miranda 150 (HUEFS); Prado, 17²0'27"S, 39²13'15"W, 31 jul. 1984 (fl.), J.C.A. Lima et al. 134 (CEPEC); Ruy Barbosa, $12^{\circ} 19^{\prime} 07^{\prime \prime S}, 40^{\circ} 29^{\prime} 26^{\prime \prime} \mathrm{W}, 17 \mathrm{dez} .2004$ (fl.) L.P. Queiroz et al. 9871 (HUEFS); Salvador, 12 ${ }^{\circ} 56^{\prime} \mathrm{S}, 38^{\circ} 21^{\prime} \mathrm{W}, 12$ dez. 1985 (fl.), L.R. Noblick 4487 (HUEFS); Santa Terezinha, 1252'05"S, 39²8'47"W, 4 mar. 2001 (fl., fr.), L.P. Queiroz 6493 (HUEFS); Senhor do Bonfim, 10²1'57"S, 40 ${ }^{\circ} 11^{\prime} 51^{\prime \prime W}, 13$ jul. 2005 (fl.), $D$.

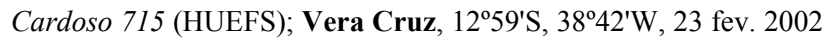
(fl.), M.V. Moraes 507 (HUEFS).

Costus spiralis é a espécie de Costaceae mais comum na Bahia. Suas inflorescências são vistosas, sendo bastante usadas como ornamentais; as flores costumam ser visitadas por beija-flores como o Ramphodon naevius e o Phaethornis spp. e os frutos dispersados por aves e formigas (Araújo \& Oliveira 2007). É popularmente conhecida como cana-demacaco e cana-do-brejo, sendo utilizada na medicina popular em tratamentos de afecções urinárias, cálculo renal, no processo de cicatrização, perda do excesso de líquido no corpo e controle da diabetes (Medeiros et al. 2004; Silva \& Parente 2004).

\section{AgRADECIMENTOS}

Aos curadores dos herbários, pelo acesso às coleções; à Carla de Lima, pela arte final das ilustrações; e ao Jomar Jardim, pelas fotografias. À CAPES, pelas bolsas de Mestrado concedidas a ABJ e de Produtividade em Pesquisa/CNPq a AMG e RPO (PQ Senior e PQ1-D, respectivamente). À FAPESB (processo APR 162/2007) e ao CNPq, pelo auxílio financeiro ao Projeto Flora da Bahia (processos 562278/2010-9 e 483909/2012-2).

\section{REFERÊNCIAS}

André, T.J.C.; Specht, C.; Salzman, S.; Palma-Silva, C. \& Wendt, T. 2015. Evolution of species diversity in the genus Chamaecostus (Costaceae): molecular phylogenetics and morphometric approaches. Phytotaxa 4: 265-276.

APG IV. 2016. An update of the Angiosperm Phylogeny Group classification for the orders and families of flowering plants. Botanical Journal of the Linnean Society 161: 105-121.

Araújo, F.P. \& Oliveira, P.E. 2007. Biologia floral de Costus spiralis (Jacq.) Roscoe (Costaceae) e mecanismos para evitar a autopolinização. Revista Brasileira de Botânica 30(1): 61-70.

BFG [the Brazil Flora Group] 2015. Growing knowledge: an overview of Seed Plant diversity in Brazil. Rodriguésia 66(4): 1085-1113.

IBAMA [Instituto Brasileiro do Meio Ambiente e dos Recursos Naturais Renováveis] 1992. Lista oficial das espécies da flora brasileira ameaçadas de extinção. Diário Oficial. Portaria 006/92-N de 15 de janeiro de 1992. Disponível em http://www.ibama.gov.br/lista-de-especies-ameacadas-deextincao; acesso em 20 fev. 2016.

Maas, P.J.M. 1972. Costoideae (Zingiberaceae). Flora. Neotropica. Vol. 8. New York Botanical Garden, New York, p. 1-140.

Maas, P.J.M. 1977. Costoideae (Additions). Flora. Neotropica. Vol. 18. New York Botanical Garden, New York Botanical, p. 162-218.

Maas, P. \& H. Maas. 2016. Costaceae. In: Lista de Espécies da Flora do Brasil. Jardim Botânico do Rio de Janeiro. Disponível em http://floradobrasil.jbrj.gov.br/jabot/floradobrasil/FB110631; acesso em 18 jan. 2016.

Maas, P.J.M. \& H. Maas-van de Kamer. 2010. Costaceae. In: R.C. Forzza, J.F.A. Baumgratz, C.E.M. Bicudo, D.A.L. Canhos, A.A. Carvalho Jr., A.F. Costa, D.P. Costa, M. Hopkins, P.M. Leitman, L.G. Lohmann, L.C. Maia, G. Martinelli, M. Menezes, M.P. Morim, M.A. Nadruz-Coelho, A.L. Peixoto, J.R. Pirani, J. Prado, 
L.P. Queiroz, V.C. Souza, J.R. Stehmann, L. Sylvestre, B.M.T. Walter \& D. Zappi, (eds), Catálogo de Plantas e Fungos do Brasil. Vol. 2. Instituto de Pesquisas Jardim Botânico do Rio de Janeiro, Rio de Janeiro, p. 895-896.

Maas-van de Kamer, H. \& Maas, P.J.M. 2003. Costaceae. In: M.G.L. Wanderley, G.J. Sheperd, A.M. Giuletti, T.S. Melhem \& M. Kirizawa (eds), Flora Fanerogâmica do Estado de São Paulo. Vol. 3. FAPESP \& Hucitec, São Paulo, p. 63-65.

Medeiros, M.F.T.; Fonseca, V.S. \& Andreata, R.H.P. 2004. Plantas medicinais e seus usos pelos sitiantes da Reserva do Rio das Pedras, Mangaratiba, RJ, Brasil. Acta Botanica Brasilica 18: 391-399.

MMA [Ministério do Meio Ambiente] 2008. Instrução normativa atualizando a lista oficial das espécies da flora brasileira ameaçadas de extinção. Diário Oficial. Disponível em http://www.mma.gov.br/estruturas/179/_arquivos/179_0512200 8033615.pdf; acesso em 20 fev. 2016.
Silva, B.P. \& Parente, J.P. 2004. New steroidal saponins from rhizome of Costus spiralis. Zeitschrift fur Naturforschung, C, Journal of Biosciences 59: 81-85.

Souza, V.C. \& Lorenzi, H. 2008. Botânica Sistemática: guia ilustrado para identificação das famílias de angiospermas da flora brasileira, baseado em APG II. Instituto Plantarum, Nova Odessa.

Specht, C.D. \& Stevenson, D.W. 2006. A new phylogeny-based generic classification of Costaceae (Zingiberales). Taxon 55: 153-163.

Tintino, R.S.; Guedes, M.M.G.; Cunha B.A.F.; Santos, A.K.K.; Matias, F.F.E.; Braga, M.B.F.M.; Andrade, J.C.; Souza, E.S.; Freitas, M.A.; Alencar, L.B.B.; Costa J.G. M. \& Coutinho, H.D.M. 2013. Avaliação in vitro da atividade antimicrobiana e moduladora dos extratos etanólico e hexânico de bulbo de Costus arabicus. Journal of Biosciences 29(3): 732-738.

\section{LISTA DE EXSICATAS}

Amorim, A.M. 949 (2.1); Bacelar, T.G. 53 (2.1); Belém, R.P. 2274 (1.2); Brito, H.S. 37 (2.1); Cardoso, D. 715 (2.3); Carvalho, A.M. 791 (2.3); Costa, J. 154 (2.3), 447 (1.2); Filho, L.E.M. 2980 (1.1); França, F. 937 (1.2), 3673 (2.3); Giulietti, A.M. 2550 (2.3); Grupo Pedra do Cavalo 456 (2.3), 460 (1.2); Guedes, M.L. 14855 (2.3); Hage, J.L. 2056 (2.3), 2256 (2.3); Harley, R.M. 16573 (2.3), 17583 (2.1), 18341, 21844 (2.3), 22226 (2.1), PCD 2797 (2.3); Jardim, J.G. 4549 (1.2); Lanna, J.P. 1512 (2.2); Leite, K.R.B. 75 (1.2); Lima, J.C.A. 134 (2.3); Lombardi, J.A. 5530 (1.2); Maas, P.J.M. 6970 (2.3), 6972 (2.2); Machado, M. 94 (1.2); Matos, E.N. 709 (2.1); MattosSilva, L.A. 368, 1053, 1804 (1.1), 2256 (2.1), 3313 (2.3), 3701, 3979, 4502, 4739 (2.1); Mayo, S. 718 (1.2); Miranda, E.B. 150 (2.3); Moraes, M.V. 507 (2.3); Mori, S.A. 9351 (1.2), 9551 (2.2), 10753 (1.2), 11599 (2.3); Noblick, L.R. 1905, 3170, 3214, 3987, 4487 (2.3); Nunes, T.S. 756 (2.1); Pengel, H.O. 1 (2.3); Pinheiro, R.S. 1742 (1.2), 1747 (1.1), 1771 (2.1); Queiroz, L.P. 6319, 6493, 9775, 12085 (2.3); Sant'Ana, S.C. 268 (2.2); Santana, D.L. 527 (2.1); Santos, T.S. 322 (2.3), 828, 893, 1157 (1.1), 1301 (1.2), 1548, (2.1), 1654 (1.1), 1661 (1.2), 1974, 2380 (2.1), 3004 (2.3), 3005, 3237 (2.2), 3247 (2.1), 4213 (2.2); Silva, M.M. 58 (2.3); Thomas, W.W. 9329 (1.1), 10858 (1.2), 11304 (2.1), 11937, 13401 (1.2); Vinha, S.G. 75 (2.1). 